\title{
Article \\ Effect of Unmeasured Time Hours on Occupational Noise Exposure Assessment in the Shipbuilding Process in Korea
}

\author{
Jaewoo Shin ${ }^{1,2}$, Seokwon Lee ${ }^{1,3}\left(\mathbb{D}\right.$, Kyoungho Lee ${ }^{4, *,+}$ and Hyunwook Kim ${ }^{1,5, *, \dagger}$ \\ 1 Department of Public Health, Graduate School, The Catholic University of Korea, Seoul 06591, Korea; \\ sjw1063@cmcnu.or.kr (J.S.); swlee23@korea.kr (S.L.) \\ 2 Center for Occupational and Environmental Medicine, Seoul Saint Mary's Hospital, \\ The Catholic University of Korea, Seoul 06591, Korea \\ 3 Environmental Health Research Department, National Institute of Environmental Research, \\ Incheon 22689, Korea \\ 4 Division of Population Health Research, Department of Precision Medicine, National Institute of Health, \\ KDCA, Cheongju 28160, Korea \\ 5 Department of Preventive Medicine, College of Medicine, The Catholic University of Korea, \\ Seoul 06591, Korea \\ * Correspondence: khlee3789@korea.kr (K.L.); hwkim@catholic.ac.kr (H.K.); Tel.: +82-43-719-6710 (K.L.); \\ +82-2-2258-7363 (H.K.) \\ + These corresponding authors have equally contributed to this study.
}

check for

updates

Citation: Shin, J.; Lee, S.; Lee, K.; Kim, H. Effect of Unmeasured Time Hours on Occupational Noise Exposure Assessment in the Shipbuilding Process in Korea. Int. J. Environ. Res. Public Health 2021, 18, 8847. https://doi.org/10.3390/ ijerph18168847

Academic Editors: Massimo Ralli, Richard Salvi, Adam Sheppard and Paul B. Tchounwou

Received: 28 June 2021

Accepted: 19 August 2021

Published: 22 August 2021

Publisher's Note: MDPI stays neutral with regard to jurisdictional claims in published maps and institutional affiliations.

Copyright: (C) 2021 by the authors Licensee MDPI, Basel, Switzerland. This article is an open access article distributed under the terms and conditions of the Creative Commons Attribution (CC BY) license (https:// creativecommons.org/licenses/by/ $4.0 /)$
Abstract: Occupational noise is known to be one of the most hazardous risk factors, frequently exceeding the exposure limit thus causing hearing loss and other health outcomes among many field workers in various industries and workplaces. This study aims to characterize the levels of occupational noise exposure during the daily working hours and break periods (sampling preparation and lunch break), identify work-related characteristics affecting the noise exposure levels when including or excluding the break periods and finally determine the most effective approach for occupational noise exposure assessment by using the Korean and U.S. OSHA's guidelines. A total of 1575 workers employed by a large shipbuilding company participated in this study, and the historical exposure datasets of noise dosimeters, collected from 2016 to 2018, were classified by characteristics. A threshold level (TL) for the noise dosimeter was set as a value of $80 \mathrm{dBA}$ during the break periods, including the preparation time for sampling instruments and one hour for the lunch break. The shipbuilding workers were exposed to high levels of occupational noise during the break periods, especially for those working in heating, grinding, and power processes in the painting-related departments. Out of 1575 samples, most cases were related to the preparation time ( $N=1432,90.9 \%)$ and lunch break $(N=1359,86.9 \%)$. During the break time, the levels of noise exposure were measured depending on task-specific characteristics. When including the break time, the noise levels increased by approximately $1 \mathrm{dBA}$ during the break, combining $0.8 \mathrm{dBA}$ in the lunch hours and $0.2 \mathrm{dBA}$ for the preparation of the sampling instrument. When excluding the break time, the levels of noise exposure collected using a Korean Occupational Safety and Health Administration (KOSHA) guide tended to be underestimated compared to those using the U.S. OSHA method. When including the break times, the proportion of noise exposure levels exceeding the compliance exposure limit declined from $37.9 \%$ to $34.5 \%$, indicating that the break times might affect the decrease in the noise exposure levels. Taken together, shipbuilding workers could possibly be exposed to much greater amounts of noise exposure during break times in the shipbuilding processes, and the noise exposure levels in the department of painting were high. Therefore, it is recommended that industrial hygienists collect exposure monitoring data of occupational noise one hour after their job tasks begin and then consecutively monitor the noise exposure levels for at least $6 \mathrm{~h}$ including the break periods for each day.

Keywords: break period; hearing protection; noise; occupational noise exposure; shipbuilding process; unmeasured time hours 


\section{Introduction}

Occupational noise exposure is one of the most important risk factors causing hearing loss among workers in a variety of industries and workplaces, and approximately $16 \%$ of manufacturing workers suffer from hearing loss with serious consequences [1], including irritation, sleep disorders, daytime sleepiness, metabolic syndrome, hypertension, and cardiovascular disease, due to acute or chronic exposure to occupational noise [2-7]. In Korea, occupational noise is known to be one of the most hazardous workplace risk factors, frequently exceeding the occupational exposure limit (OEL) during quantitative exposure assessments in a large number of industries and workplaces in the past [8-10].

To prevent occupational hearing loss, it is important that a comprehensive evaluation be performed to quantitatively characterize all levels of cumulative noise exposure during a full shift of fixed jobs, thus identifying the task-based exposure profiles for individual workers [11]. In general, personal noise exposure is determined as a daily hour timeweighted average ( 8 h-TWA) value using a cumulative noise meter measured within a radius of $30 \mathrm{~cm}$ from the ears of the worker over 6 hours and then compared to the established OEL, $85 \mathrm{dBA}$, in Korea [12]. Most studies suggested that exposure monitoring samples consecutively collected during a full shift of working hours per day provides the most accurate noise exposure assessment [13-15]. The U.S. Occupational Safety and Health Administration (OSHA) suggested that noise exposure assessment be performed to collect full shift monitoring samples for at least $7 \mathrm{~h}$ per day while excluding any less than $1 \mathrm{~h}$ break time as unmeasured periods [16]. However, the Ministry of Employment and Labor (MoEL) defined the length of noise exposure monitoring samples to be over 6 hours per day considering the real-world work environment in Korea [17].

In Western countries, some prestigious academic societies and governmental institutions, including the British Occupational Hygiene Society (BOHS) [18], the American Industrial Hygiene Association (AIHA) [19], and the OSHA [20], have established and validated the OEL of noise exposure and conduct occupational exposure assessments for compliance purposes to determine whether the measured levels of noise exposure exceed the established OEL. Several studies have also recommended that a comprehensive occupational exposure evaluation should access all types of physical and chemical agents, including noise, thus establishing task-specific exposure profiles among individual workers collected during daily working hours [21,22]. A previous study reported that the annual levels of occupational noise exposure were significantly decreasing when analyzing the U.S. OSHA's Integrated Management Information System (IMIS) database, which includes all industries 1979-2013 in the North American Industry Classification System (NAICS), including shipbuilding and repair, and comparing the results of quantitative exposure measurements to the permissible exposure limit (PEL), $90 \mathrm{dBA}$, and action level (AL), $85 \mathrm{dBA}$ [23].

In Korea, occupational exposure assessment has focused on the analysis of a small number of monitoring samples collected for only a few workers representing each occupation (job title) or department, instead of using similar exposure groups (SEGs) classified based on detailed qualitative information on the magnitude and frequency of noise exposure in the shipbuilding industry [24]. This approach has been used simply because detailed quantitative information on exposure profiles and associated determinants can be primarily collected during exposure monitoring events in real-world workplaces. Recent studies have shown the patterns and characteristics of underwater radiated noise from small ships and ducts using computational fluid dynamics (CFD) programs [25], and case studies have also suggested a new engineering approach to effectively reduce noise exposure levels in the work environment using a noise simulation [26,27]. However, no study has been previously performed to assess occupational noise exposures for a large group of workers engaged in shipbuilding processes in the shipyard industry using qualitative exposure information on work-related characteristics and evaluate the effect of unmeasured time hours for lunch break and instrument preparation when including or excluding break hours, on the average levels of noise exposure, thus determining whether or not they are exceeding the OELs established by the Korean and U.S. OSHA's guidelines. 
Therefore, this study aims to characterize the levels of occupational noise exposure during the break period (sampling preparation and lunch break hour) among a large number of manufacturing workers in the shipbuilding industry, identify several workrelated characteristics affecting the noise exposure levels when including or excluding the break periods during the exposure monitoring, and statistically comparing the average levels of noise exposure for different groups of workers to determine whether or not they are exceeding the regulatory limit values using both Korean and the U.S. OSHA's guidelines. In doing so, we ultimately focused on identifying the most applicable approach to noise exposure assessment while considering the work-related characteristics, patterns, and other factors of daily exposure measurements among individual workers in the shipbuilding industry in Korea.

\section{Materials and Methods}

\subsection{Selection of Study Subjects}

We conducted occupational exposure assessment for full-time regular and subcontracted workers affiliated with a total of 104 shipbuilding and vendor companies located in the southern area of the Republic of Korea from 1 January 2016 to 31 December 2018. We collected the exposure monitoring data using noise dosimeters for a total of 6198 workers in the targeted shipyard work environments. Of the 6198 eligible participants, their exposure data indicated an unmeasured period of less than $1 \mathrm{~h}$ per day (i.e., over $7 \mathrm{~h}$ of daily working hours), and they were included in the first step. Then, we excluded some participants in reference to Middendorf [23] if any of the following criteria were satisfied: (1) if the daily period of exposure monitoring time was less than $7 \mathrm{~h}$ prior to 4 p.m.; (2) if either exposure data or work-related information (e.g., department, subtask, employment type, etc.) necessary for the classification and determination of exposure profiles for individual workers was lacking or uncertain; (3) if the $8 \mathrm{~h}$-TWA value was either $60 \mathrm{dBA}$ and/or less or $120 \mathrm{dBA}$ and/or above, and (4) if there was an error in the historical exposure data (e.g., DOSE (\%) values, etc.). Consequently, a total of 1575 shipbuilding workers were selected as the study subjects after excluding some participants $(N=4623)$ according to the criteria mentioned above (Figure 1). This study was approved by the Institutional Review Board (IRB) of the Catholic University of Korea College of Medicine, Seoul, Republic of Korea (IRB approval No. MC13QASI0043).

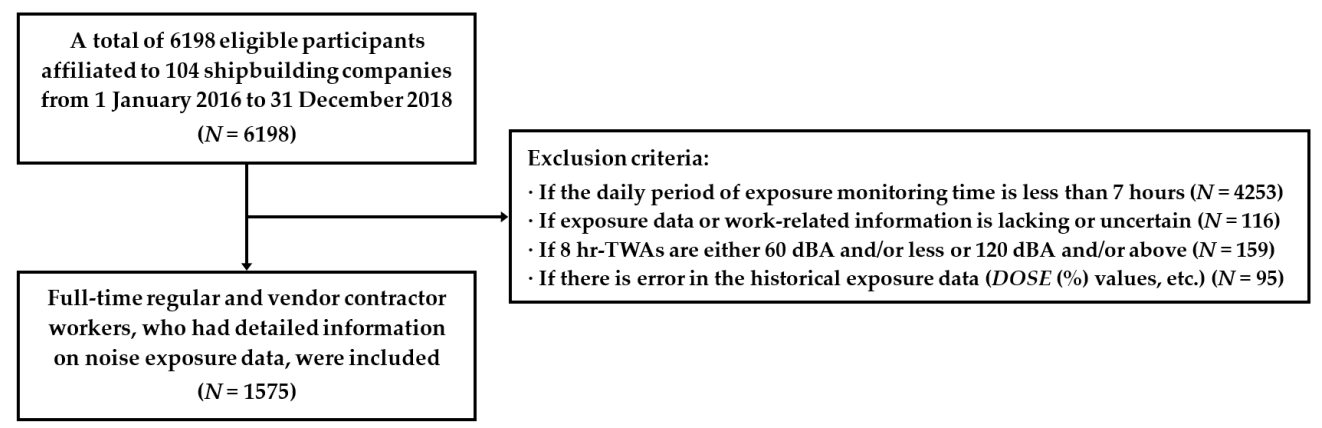

Figure 1. Flow diagram for selection of study subjects.

\subsection{Data Collection}

We performed data cleaning and established a new database for analyzing the cumulative noise exposure data of 1575 workers using the "dBLink" package (version 3.3.0.5, Cirrus Research plc, Hunmanby, North Yorkshire, UK). The characteristics of the measuring instrument were identified and classified by the collected information on the monitoring year and dates, equipment number, etc., using the cumulative noise exposure data collected from the legal work environment measurement during 2016-2018. Historical exposure measurement data were collected using a cumulative noise dosimeter instrument (CR 110A Dozebage, Circus, EU), which was determined to be suitable for ANSIS1-25-1978. At this point, the hearing correction circuit of the noise meter was characterized by its A-type 
characteristics, its operation was slow, and its metric setting criteria were set to Threshold (TL) $80 \mathrm{~dB}$, Exchange Rate (ER) $5 \mathrm{~dB}$, Response Slow, and Criterion (C-90) according to the Ministry of Employment and Labor regulation No. 2018-62 and the U.S. OSHA's hearing preservation program.

Furthermore, the authors collected data from their work environment measurement staff each time they performed legal work environment measurements 2016-2018 of all relevant information necessary for the classification of the noise exposure group of the participants. We also de-identified and coded the participants' personal information (e.g., name, age, gender, date of birth, phone number, etc.). After completing data collection, cleaning, and classification, all authors carefully reviewed and cross-checked all of the collected datasets to determine if there was any miswritten error or missing or incomplete information among these study subjects. Then, the suitability was checked with an officer of the Environmental Safety Team, and the repeated processes of QA/QC were conducted to revise such misleading information in the datasets.

\subsection{Classification of Job and Subtasks}

To develop SEGs, we collated detailed information on work-related characteristics of exposure, including working environment, department, employment type, manufacturing process, job title, and subtasks, for a total of 1575 workers (full-time regular and vendor contractor) in the shipbuilding industry and interpreted the definitions and descriptions (examples) for all classified characteristics of exposure as shown in Table 1.

Table 1. Characteristics of work environment, department, employment type, and occupation (job task) in the shipbuilding process in Korea.

\begin{tabular}{|c|c|}
\hline Characteristics & Description \\
\hline \multicolumn{2}{|l|}{ Work environment } \\
\hline Outside & Job tasks performed outside the workplace (e.g., hull assembly, outfitting, hull painting, sea trial) \\
\hline Inside & $\begin{array}{l}\text { Job tasks performed inside the workplace (e.g., subassembly, panel assembly, unit assembly, } \\
\text { pre-outfitting, pre-painting) }\end{array}$ \\
\hline Combined & Job tasks performed both outside and inside the workplace (e.g., sub-departments) \\
\hline \multicolumn{2}{|l|}{ Department } \\
\hline Hull assembly & $\begin{array}{l}\text { The completed larger units are then moved to the graving dock, shipway or final assembly area. } \\
\text { Here, the larger units are joined together to form the vessel }\end{array}$ \\
\hline Hull painting & $\begin{array}{l}\text { Hull surface preparation and painting on repair ships is normally performed when the ship is fully } \\
\text { drydocked (i.e., on the graving dock of a floating drydock). }\end{array}$ \\
\hline Sea trial & $\begin{array}{l}\text { After completion of the outfitting phase, the ship undergoes both dock and sea trials, during which } \\
\text { all the ship's systems are proved to be fully functional and operational. }\end{array}$ \\
\hline Outfitting & $\begin{array}{l}\text { The process of installing parts and various subassemblies (e.g., piping systems, ventilation } \\
\text { equipment, electrical components) on the block prior to joining the blocks together at erections. After } \\
\text { the ship is launched, it enters the outfitting phase. A large amount of time and equipment are } \\
\text { required. The work includes the fitting of cabling and piping, the furnishing of galleys and } \\
\text { accommodations, insulation work, installation of electronic equipment and navigation aids, and } \\
\text { installation of propulsion and ancillary machinery. }\end{array}$ \\
\hline Subassembly & $\begin{array}{l}\text { The basic component of shipbuilding is steel plate. The plates are cut, shaped, bent or otherwise } \\
\text { manufactured to the desired configuration specified by the design. }\end{array}$ \\
\hline Panel assembly & $\begin{array}{l}\text { The plates are joined into various units and subassemblies. At this juncture, piping, electrical, and } \\
\text { other utility systems are assembled and integrated into the units. }\end{array}$ \\
\hline & The units are assembled using automatic or manual welding or a combination of the two. \\
\hline Unit assembly & $\begin{array}{l}\text { The units or subassemblies are usually then transferred to an open-air platen or lay down area where } \\
\text { erection, or joining of assemblies, occurs to form even larger units or blocks }\end{array}$ \\
\hline Block painting & blasted to ensure proper profiling, and painted \\
\hline Misc. & The rest of the departments \\
\hline \multicolumn{2}{|l|}{ Employment type } \\
\hline Full-time worker & Directly employed by the shipbuilding company \\
\hline Contractor worker & Affiliated to several vendor companies \\
\hline
\end{tabular}


Table 1. Cont.

\begin{tabular}{ll}
\hline \multicolumn{1}{c}{ Characteristics } & \multicolumn{1}{c}{ Description } \\
\hline Occupation (job task) & Removing and cleaning substances, including scale, rust, etc., on the surface of the block \\
Blasting & Removing paint, rust, etc. applied to parts requiring modification outside of a ship \\
Power & Spraying paint using a compressed air gun \\
Spray & Touching up paint using a small brush and pulley \\
Touch up & Bending an iron plate by heating \\
Heating & Cutting and grinding scales of weld metal parts \\
Grinder & Sea trial commander responsible for managing the vessel and all personnel on board \\
Sea trial & Signaling for crane, forklift truck, etc. \\
Signal & Joining and welding between the steel plates by heating and melting \\
Welding & Preparation and classification of raw materials \\
Material classification & Cutting steel plates into desired shapes and sizes \\
Cutting & Fitting up steel plates prior to pre-welding \\
Fit-up & The rest of job tasks \\
Misc. &
\end{tabular}

\subsection{Occupational Exposure Assessment}

The original timetable of occupational exposure assessment was from 8 a.m. to 5 p.m. per day, and the break periods included preparation time for exposure sampling instruments (before $8 \mathrm{a} . \mathrm{m}$.) and $1 \mathrm{~h}$ for a lunch break (from 12 p.m. to 1 p.m.). We measured the levels of occupational noise exposure (dBA), including the break periods, and collated the historical exposure data measured over $7 \mathrm{~h}$, including the unmeasured sampling period (less than $1 \mathrm{~h}$ ). We assumed that the noise exposure levels measured during the full-shift sampling period were comparable to those collected during the unmeasured sampling period, and then the same value of DOSE (\%) was applied to calculate the $8 \mathrm{~h}$-TWA (i.e., $L_{A V G}$ ) values [12].

All datasets of occupational noise exposure measurements $(N=1575)$ were classified by the factor of work-related characteristics (e.g., type of work environment, department, employment type, and job task) and then individually matched to one of the classified categories for each characteristic, depending on our professional judgment about the data input process. The values of $8 \mathrm{~h}$-TWA $\left(L_{A V G}\right), D O S E(\%)$, and exposure sampling periods that included the lunch break $(1 \mathrm{~h})$ from the individual datasets were entered into a software program, the dBLink package version 3.3 (Cirrus Research plc, Hunmanby, North Yorkshire, UK), and the same calculations were repeated using different values for $8 \mathrm{~h}$-TWA, DOSE (\%) and sampling periods between segments divided into different timetables of exposure sampling (e.g., before 8 a.m., from 8 a.m. to 4 p.m., after 4 p.m.).

Regardless of including the break periods (preparation of sampling instrument and lunch break hours), $L_{A V G}$ was calculated using Equations (1) and (2) with detailed exposure information on work-related characteristics (e.g., working condition, department, employment type, and job tasks) [20]. According to the KOSHA guide [12,13], the average noise level $\left(L_{A V G}\right)$ during the noise monitoring period was calculated from the measured data by using a value of DOSE (\%) for lunchtime and one hour for lunchtime out of the total measurement in Equation (2). Then, each time-weighted average (TWA) value with a change in the monitoring time (increase in the unmeasured time) was also obtained using Equations (1) and (2). The abnormal time (over 8 hours) was calculated by modifying the 8-hour exposure limit, $90 \mathrm{dBA}$, using Equation (3).

The first formula of cumulative equivalent noise level, Leq (dB), was calculated using Equation (1) as follows:

$$
\operatorname{Leq}(\mathrm{dB})=16.61 \times \log \frac{\left(t_{1} \times 10^{\frac{S P L_{1}}{16.61}}\right)+\left(t_{2} \times 10^{\frac{S P L_{2}}{16.61}}\right)+\cdots+\left(t_{n} \times 10^{\frac{S P L_{n}}{16.61}}\right)}{t_{1}+t_{2}+\cdots+t_{n}}
$$

$t$ : sampling period (min), SPL: sound pressure level (dBA), $E R=5 \mathrm{~dB}$. 
A second formula for $8 \mathrm{~h}$-TWA $\left(L_{A V G}\right)$ and DOSE (\%) values $(C L=90, E R=5 \mathrm{~dB}$, $C T=8 \mathrm{~h}$ ) was calculated using Equation (2) as follows:

$$
\begin{gathered}
T W A_{T}=16.61 \times \log \left(\frac{C T \times D O S E(\%)}{T \times 100 \%}\right)+90 \mathrm{dBA} \\
T W A_{T}=16.61 \times \log \left(\frac{D O S E(\%)}{T \times 12.5 \%}\right)+90 \mathrm{dBA} \\
\operatorname{DOSE}(\%)=\left(\frac{C_{1}}{T_{1}}+\frac{C_{2}}{T_{2}}+\cdots+\frac{C_{n}}{T_{n}}\right) \times 100
\end{gathered}
$$

$C$ : daily working hour, $T$ : permissible exposure time corresponding with measured SPL.

The third formula $(E R=5 \mathrm{~dB})$ converted with time $(T)$ and noise level $(L)$ is defined as Equation (3) as follows:

$$
T=\frac{8}{2^{\frac{(L-90)}{5}}}
$$

We compared occupational noise exposures using the U.S. OSHA method and KOSHA guideline (Table 2). When the break time was included, the average noise levels $\left(L_{A V G}\right)$ using the U.S. OSHA method and KOSHA guideline were the same. However, the KOSHA guide did not adjust the OEL for abnormally longer working hours $(\geq 8 \mathrm{~h})$. When excluding the break periods, the KOSHA guide tends to underestimate compared to the U.S. OSHA method because the $L_{A V G}$ values are evaluated by using a formula that includes DOSE (\%)

\begin{tabular}{|c|c|c|c|c|c|c|}
\hline \multirow{2}{*}{ Methodology } & \multicolumn{3}{|c|}{$\begin{array}{c}\text { Including Entire Break Time }{ }^{1} \\
(9 \mathrm{~h})\end{array}$} & \multicolumn{3}{|c|}{$\begin{array}{c}\text { Excluding Entire Break Time }{ }^{2} \\
(8 \mathrm{~h})\end{array}$} \\
\hline & Time (1 h) & DOSE (\%) & OEL & Time (1 h) & DOSE (\%) & OEL \\
\hline OSHA method & Included & Included & $89.2 \mathrm{dBA}$ & Excluded & Excluded & $90 \mathrm{dBA}$ \\
\hline KOSHA guide & Included & Included & $90 \mathrm{dBA}$ & Excluded & Included & $90 \mathrm{dBA}$ \\
\hline
\end{tabular}
generated during the break time but excludes lunchtime (for $1 \mathrm{~h}$ ).

Table 2. Comparison of noise exposure assessment methods between the U.S. OSHA method and KOSHA guide.

${ }^{1} L_{A V G}$ is calculated including two values of Time $(1 \mathrm{~h})$ and DOSE (\%) in Equation (2) when using the U.S. OSHA method and KOSHA guide. ${ }^{2} L_{A V G}$ is calculated excluding the two values of Time $(1 \mathrm{~h})$ and DOSE (\%) when using the U.S. OSHA method, but DOSE (\%) was only included in Equation (2) when using the KOSHA guide.

\subsection{Statistical Analysis}

All statistical analyses were performed using the SPSS software package version 18.0 for Windows (IBM Corporation, Armonk, NY, USA). The level of noise exposure during the break period (preparation and lunch hours) was determined by DOSE (\%) measured using a noise dosimeter with a threshold (TL) of $80 \mathrm{dBA}$. The value of $L_{A V G}$ was calculated using the measured time period (in hours) and DOSE (\%) for each measurement classified by characteristics (work environment, department, employment type, or job task). The paired $t$-test was also performed to compare the $L_{A V G}$ values for the same measurements during different sampling timetables with or without the break periods. The paired t-test and McNemar test were applied to compare the noise exposure levels measured using the different approaches of the Korean and OSHA's hearing conservation program (HCP) by characteristics. Finally, the intraclass correlation coefficients (ICCs) were calculated to compare the average levels of occupational noise with the OEL values of $90 \mathrm{dBA}(8 \mathrm{~h})$ and $89.2 \mathrm{dBA}(9 \mathrm{~h})$ by decreasing $1 \mathrm{~h}$ for daily exposure sampling timetables from the beginning to the end of exposure sampling, and the McNemar test was performed to determine the most relevant timetable among the different sampling timetables with $p$-values at a significance level of 0.05 .

\section{Results}

During the break periods, including preparation time for sampling instruments (e.g., pre- and post-calibration, etc.) and the $1 \mathrm{~h}$ lunch break, the noise exposure lev- 
els were individually measured for a total of 1575 shipbuilding workers engaged in various job tasks. Out of 1575 exposure datasets, high levels of noise exposure were associated with preparation $(N=1432,90.9 \%)$ and the lunch break $(N=1359,86.9 \%)$. Figure 2 shows noise exposure levels and patterns of all study subjects $(N=1575)$ measured during the entire daily working hours, including break time periods, and the ranges of occupational noise levels for 12 13 p.m. (lunch break) were comparable to those measured for 9 11 a.m. (after beginning the daily job tasks) and 13 15 p.m. (after lunch break). Figure 3 also shows that the patterns of noise exposure measured during the break periods, (a) prior to the beginning of job tasks for the preparation of sampling instruments ( $~ 8$ a.m.) and (b) lunch break hour (12 13 p.m.), frequently exceeded the OEL, $90 \mathrm{dBA}$.

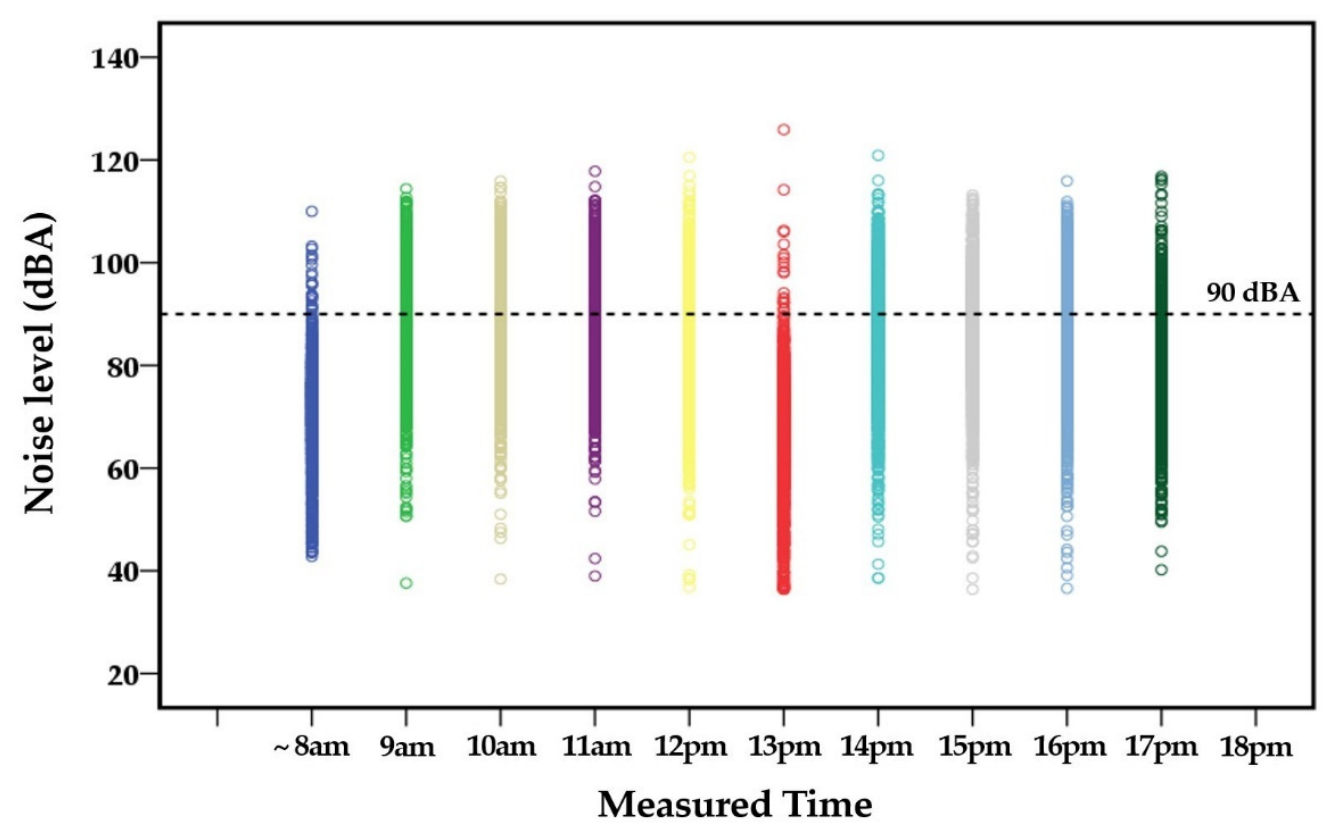

Figure 2. Noise exposure levels of all study subjects $(N=1575)$ at each measured time per day.

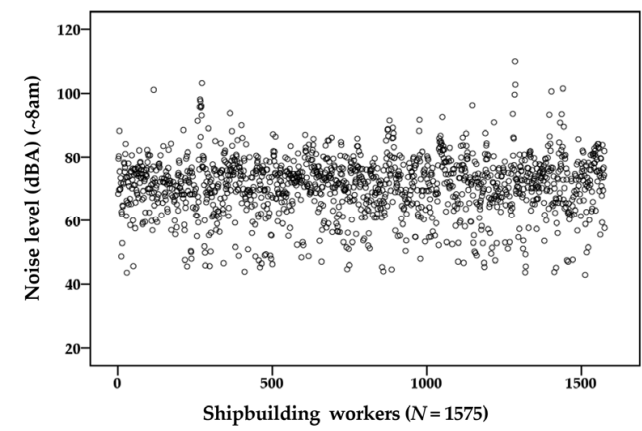

(a)

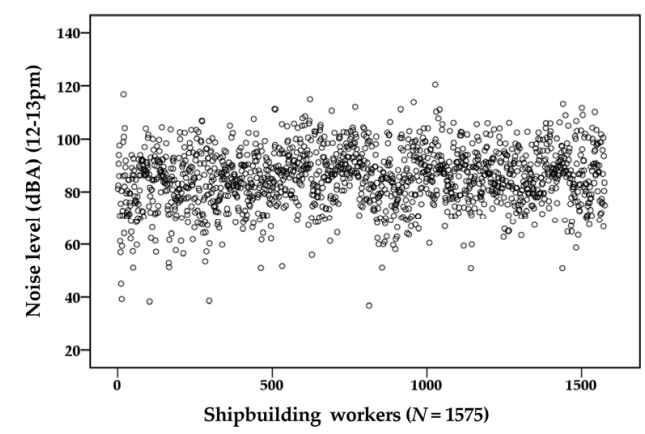

(b)

Figure 3. Patterns of noise exposure levels during the break time periods: (a) preparation of sampling instruments ( 8 a.m.), (b) lunch break hour (12-13 p.m.).

Table 3 shows the average levels of noise exposure $\left(L_{A V G}\right)$ during the break periods by each characteristic, and they were significantly higher inside $(81.8 \mathrm{dBA})$ than outside the workplaces $(71.8 \mathrm{dBA})$ during the preparation time. However, $L_{A V G}$ was higher outside (83.5 dBA) than inside the workplaces (77.5 dBA) during the lunch breaks. The $L_{A V G}$ was the highest in the department of block painting $(88.9 \mathrm{dBA})$ during the preparation time but was $95.9 \mathrm{dBA}$ in the department of hull painting during the lunch hour and was similarly high in the block painting department $(87.6 \mathrm{dBA})$ during lunch break. The levels of $L_{A V G}$, $79.1 \mathrm{dBA}$, and $83.1 \mathrm{dBA}$ for contractor workers collected during the preparation and lunch 
break hours were also significantly higher than those of the full-time regular workers, i.e., $73.9 \mathrm{dBA}$ and $70.2 \mathrm{dBA}$, respectively. Among the 13 different job tasks, the highest levels of $L_{A V G}$ were $84.9 \mathrm{dBA}$ for blasting during the preparation and $100.9 \mathrm{dBA}$ for power tools during the lunch break.

Table 3. The measured results of occupational noise exposure during the break periods in the shipbuilding workplaces.

\begin{tabular}{|c|c|c|c|c|c|c|c|c|c|c|}
\hline \multirow{2}{*}{ Characteristics } & \multicolumn{5}{|c|}{ Preparation Time } & \multicolumn{5}{|c|}{ Lunch Break } \\
\hline & $N^{1}$ & Time (h) ${ }^{2}$ & $\operatorname{DOSE}(\%)^{3}$ & Max & $L_{A V G}{ }^{4}$ & $N^{1}$ & Time (h) ${ }^{2}$ & DOSE $(\%)^{3}$ & $\operatorname{Max}$ & $L_{A V G}{ }^{4}$ \\
\hline Overall & 1432 & 0.4 & 0.9 & 110.0 & 77.6 & 1359 & 1 & 6.1 & 125.9 & 84.8 \\
\hline \multicolumn{11}{|l|}{ Work environment } \\
\hline Outside & 583 & 0.4 & 0.4 & 91.4 & 71.8 & 548 & 1 & 5.1 & 125.9 & 83.5 \\
\hline Inside & 635 & 0.3 & 1.2 & 110.0 & 81.8 & 617 & 1 & 2.2 & 114.2 & 77.5 \\
\hline Outside/Inside & 214 & 0.4 & 0.7 & 96.2 & 75.8 & 194 & 1 & 0.9 & 89.5 & 71.0 \\
\hline \multicolumn{11}{|l|}{ Department } \\
\hline Hull assembly & 250 & 0.4 & 0.5 & 91.4 & 73.4 & 233 & 1 & 1.8 & 106.0 & 76.0 \\
\hline Hull painting & 72 & 0.4 & 0.4 & 80.8 & 71.8 & 67 & 1 & 28.5 & 125.9 & 95.9 \\
\hline Sea trial & 47 & 0.4 & 0.3 & 75.6 & 69.7 & 48 & 1 & 0.6 & 81.8 & 68.1 \\
\hline Outfitting & 214 & 0.4 & 0.4 & 90.9 & 71.8 & 200 & 1 & 2.3 & 106.3 & 77.8 \\
\hline Subassembly & 173 & 0.2 & 0.7 & 101.5 & 80.8 & 175 & 1 & 1.7 & 100.1 & 75.6 \\
\hline Panel assembly & 186 & 0.3 & 0.9 & 101.1 & 79.7 & 173 & 1 & 1.0 & 88.4 & 71.8 \\
\hline Unit assembly & 195 & 0.4 & 0.5 & 100.6 & 73.4 & 188 & 1 & 0.9 & 91.1 & 71.0 \\
\hline Block painting & 81 & 0.4 & 4.3 & 110.0 & 88.9 & 81 & 1 & 9.0 & 114.2 & 87.6 \\
\hline Misc. & 214 & 0.4 & 0.7 & 96.2 & 75.8 & 194 & 1 & 0.9 & 89.5 & 71.0 \\
\hline \multicolumn{11}{|l|}{ Employment type } \\
\hline Full-time worker & 591 & 0.3 & 0.4 & 100.6 & 73.9 & 542 & 1 & 0.8 & 87.4 & 70.2 \\
\hline Contractor worker & 841 & 0.4 & 1.1 & 110.0 & 79.1 & 817 & 1 & 4.8 & 125.9 & 83.1 \\
\hline \multicolumn{11}{|l|}{ Occupation (job task) } \\
\hline Blasting & 18 & 0.5 & 3.1 & 96.0 & 84.9 & 16 & 1 & 5.8 & 98.3 & 84.5 \\
\hline Power & 41 & 0.4 & 0.6 & 85.0 & 74.7 & 37 & 1 & 56.4 & 125.9 & 100.9 \\
\hline Spray & 57 & 0.4 & 0.4 & 81.8 & 71.8 & 56 & 1 & 1.0 & 87.1 & 71.8 \\
\hline Touch up & 24 & 0.5 & 1.1 & 87.2 & 77.5 & 22 & 1 & 1.6 & 84.8 & 75.2 \\
\hline Heating & 28 & 0.3 & 0.6 & 86.5 & 76.8 & 28 & 1 & 1.6 & 91.1 & 75.2 \\
\hline Grinder & 159 & 0.4 & 2.4 & 110.0 & 84.7 & 154 & 1 & 6.0 & 114.2 & 84.7 \\
\hline Sea trial & 23 & 0.4 & 0.4 & 75.6 & 71.8 & 24 & 1 & 0.8 & 81.8 & 70.2 \\
\hline Signal & 27 & 0.4 & 0.6 & 85.3 & 74.7 & 25 & 1 & 0.6 & 77.9 & 68.1 \\
\hline Welding & 318 & 0.3 & 0.5 & 100.6 & 75.5 & 281 & 1 & 1.1 & 86.8 & 72.5 \\
\hline Material classification & 93 & 0.3 & 0.6 & 89.5 & 76.8 & 85 & 1 & 0.9 & 81.4 & 71.0 \\
\hline Cutting & 43 & 0.2 & 0.3 & 83.9 & 74.7 & 44 & 1 & 1.2 & 85.5 & 73.1 \\
\hline Fit-up & 390 & 0.4 & 0.6 & 101.5 & 74.7 & 376 & 1 & 1.2 & 100.1 & 73.1 \\
\hline Misc. & 211 & 0.4 & 0.5 & 96.2 & 73.4 & 211 & 1 & 0.8 & 89.5 & 70.2 \\
\hline
\end{tabular}

${ }^{1}$ Subjects, who had no value of DOSE (\%) $\left(N=143\right.$ for preparation, $N=216$ for lunch break), were excluded in the analysis. ${ }^{2}$ Average of hour, DOSE (\%). ${ }^{3}$ Average of DOSE (\%). ${ }^{4}$ Average obtained from time and DOSE (\%), dBA.

In Table 4, the mean levels of occupational noise exposure by their characteristics, including and excluding the break period (preparation of instruments and lunch break hour), are described. The overall mean level of occupational noise exposure $(N=1575)$ was $88.3 \mathrm{dBA}$ when excluding the break period, and it was significantly higher than $87.3 \mathrm{dBA}$ when including the break period $(p<0.05)$. The mean levels of all work-related characteristics when excluding the break time were approximately $1 \mathrm{dBA}$ higher than those when including the break periods $(p<0.001)$. However, the differences in mean levels when excluding or including the break periods for some job tasks, such as touch up, spray, power, and material classification, were relatively small but still statistically significant $(p<0.05)$.

Figure 4 also shows the mean noise levels and percentages (\%) of the OEL (90 dBA) for all subjects $(N=1575)$ measured for three years (2016-2018). The mean noise exposure levels for all shipbuilding workers were approximately $88 \mathrm{dBA}$, and most samples did not exceed the OEL, but some peak exposure samples frequently exceeded the OEL. The noise exposure levels, converted to the percentage (\%) compared to the OEL of $90 \mathrm{dBA}$, generally did not exceed a value of $100 \%$ but showed the pattern in which some measurements were exceeded. 
Table 4. Comparison of the mean levels of occupational noise exposure depending on inclusion or exclusion of the entire break periods.

\begin{tabular}{|c|c|c|c|c|}
\hline \multirow{2}{*}{ Characteristics } & \multirow{2}{*}{$N$} & \multicolumn{2}{|c|}{$\begin{array}{c}\text { Mean Levels of Occupational Noise Exposure } \\
\text { [Average of } L_{A V G} \text { (Standard Deviation), Unit: dBA] }\end{array}$} & \multirow{2}{*}{$p$-Value } \\
\hline & & $\begin{array}{l}\text { Excluding Entire } \\
\text { Break Time ( } 8 \text { h) }\end{array}$ & $\begin{array}{l}\text { Including Entire } \\
\text { Break Time }(9 \mathrm{~h})\end{array}$ & \\
\hline Overall & 1575 & $88.3(8.0)$ & $87.3(7.9)$ & $<0.001$ \\
\hline \multicolumn{5}{|l|}{ Work environment } \\
\hline Outside & 658 & $87.5(7.7)$ & $86.5(7.6)$ & $<0.001$ \\
\hline Inside & 679 & $90.6(7.6)$ & $89.6(7.5)$ & $<0.001$ \\
\hline Outside/Inside & 238 & $84.0(7.8)$ & $83.0(7.6)$ & $<0.001$ \\
\hline \multicolumn{5}{|l|}{ Department } \\
\hline Hull assembly & 291 & 89.7 (7.6) & $88.6(7.5)$ & $<0.001$ \\
\hline Hull painting & 77 & $87.5(8.0)$ & $86.6(8.0)$ & $<0.001$ \\
\hline Sea trial & 54 & $81.4(6.1)$ & $80.4(6.0)$ & $<0.001$ \\
\hline Outfitting & 236 & $86.1(7.0)$ & $85.1(7.0)$ & $<0.001$ \\
\hline Subassembly & 188 & $90.7(7.9)$ & $89.7(7.8)$ & $<0.001$ \\
\hline Panel assembly & 191 & $90.0(7.1)$ & $88.9(7.0)$ & $<0.001$ \\
\hline Unit assembly & 213 & $92.0(6.7)$ & $90.9(6.6)$ & $<0.001$ \\
\hline Block painting & 87 & $88.6(8.9)$ & $87.8(9.0)$ & $<0.001$ \\
\hline Misc. & 238 & $84.0(7.8)$ & $83.0(7.6)$ & $<0.001$ \\
\hline \multicolumn{5}{|l|}{ Employment type } \\
\hline Full-time worker & 667 & $86.3(7.4)$ & $85.3(7.3)$ & $<0.001$ \\
\hline Contractor worker & 908 & $89.8(8.1)$ & $88.8(8.0)$ & $<0.001$ \\
\hline \multicolumn{5}{|l|}{ Occupation (job task) } \\
\hline Blasting & 18 & $90.6(7.5)$ & $89.6(7.5)$ & $<0.001$ \\
\hline Power & 45 & $93.7(7.4)$ & $92.8(7.7)$ & $<0.001$ \\
\hline Spray & 61 & $82.7(6.1)$ & $81.8(6.1)$ & $<0.001$ \\
\hline Touch up & 25 & $81.8(3.7)$ & $81.1(3.7)$ & $<0.001$ \\
\hline Heating & 30 & $100.8(5.4)$ & $99.6(5.3)$ & $<0.001$ \\
\hline Grinder & 172 & $97.3(6.5)$ & $96.2(6.4)$ & $<0.001$ \\
\hline Sea trial & 24 & $80.7(6.8)$ & $79.8(6.6)$ & $<0.001$ \\
\hline Signal & 30 & $81.9(4.6)$ & $80.9(4.5)$ & $<0.001$ \\
\hline Welding & 349 & $89.1(5.2)$ & $88.1(5.2)$ & $<0.001$ \\
\hline Material classification & 100 & $80.6(6.4)$ & $79.9(6.2)$ & $<0.001$ \\
\hline Cutting & 46 & $90.6(3.8)$ & $89.6(3.8)$ & $<0.001$ \\
\hline Fit-up & 434 & $89.3(7.1)$ & $88.2(7.1)$ & $<0.001$ \\
\hline Misc. & 241 & $82.6(6.0)$ & $81.4(1.1)$ & $<0.001$ \\
\hline
\end{tabular}

${ }^{1}$ Paired samples $t$-test for continuous variable data between groups $(p<0.05)$.
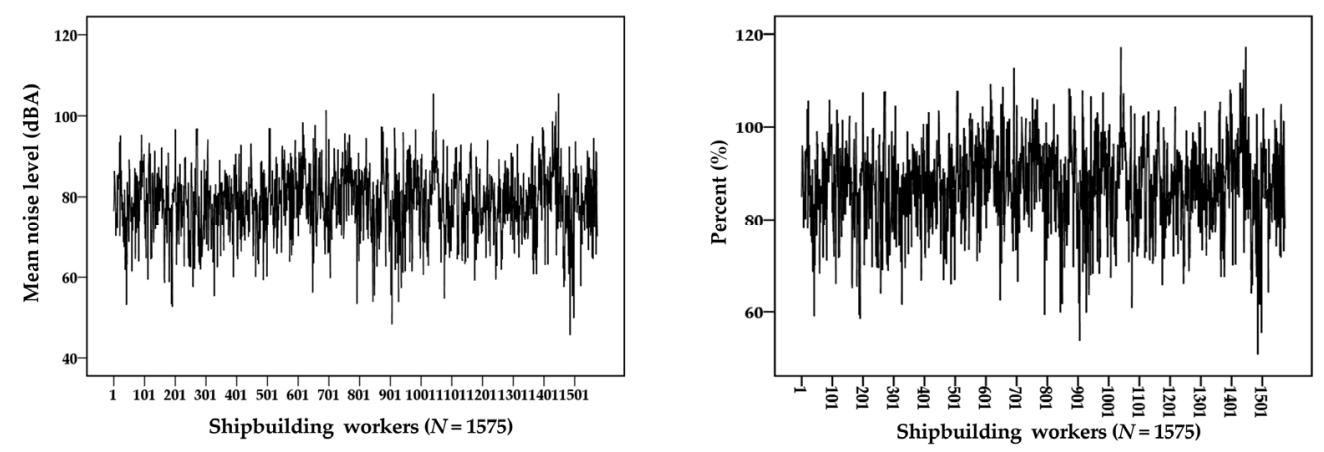

Figure 4. Mean noise levels and percent $(\%)$ for all subjects $(N=1575)$ during the shipbuilding processes.

Tables 5 and 6 show the comparative results for the mean levels of occupational noise exposure when excluding and including the break periods using the KOSHA guide and U.S. OSHA method. In the case of excluding the break period, the overall mean level 
was $87.4 \mathrm{dBA}$ using the KOSHA guide, which was significantly lower than the $88.3 \mathrm{dBA}$ using OSHA's method $(p<0.05)$ (Table 5$)$. The number and proportion exceeding the level of OEL, $90 \mathrm{dBA}$, were also different between the KOSHA guide with 597 (37.9\%) and the OSHA method with 629 (39.9\%), respectively. Furthermore, the mean levels using these two methods were also significantly different by all characteristics (independent variables), including work environment, department, employment type, and job task only when excluding the break period.

Table 5. Comparison of the mean noise exposure levels by KOSHA and OSHA method (when excluding break time, $8 \mathrm{~h}$ ).

\begin{tabular}{|c|c|c|c|c|c|c|c|}
\hline \multirow[b]{2}{*}{ Characteristics } & \multirow[b]{2}{*}{$N$} & \multicolumn{2}{|c|}{ KOSHA Guide } & \multicolumn{2}{|c|}{ OSHA Method } & \multirow[b]{2}{*}{$p$-Value ${ }^{2}$} & \multirow[b]{2}{*}{$p$-Value ${ }^{3}$} \\
\hline & & $\begin{array}{l}\text { Mean } \\
(\mathrm{SD})^{1}\end{array}$ & $\begin{array}{c}>90 \mathrm{dBA} \\
{[N(\%)]}\end{array}$ & Mean (SD) ${ }^{1}$ & $\begin{array}{c}>90 \mathrm{dBA} \\
{[N(\%)]}\end{array}$ & & \\
\hline Overall & 1575 & $87.4(8.5)$ & $597(37.9)$ & $88.3(8.0)$ & $629(39.9)$ & $<0.001$ & $<0.001$ \\
\hline \multicolumn{8}{|l|}{ Work environment } \\
\hline Outside & 658 & $86.5(8.3)$ & $220(33.4)$ & $87.5(7.7)$ & $231(35.1)$ & $<0.001$ & 0.005 \\
\hline Inside & 679 & $89.9(7.9)$ & $336(49.5)$ & $90.6(7.6)$ & $354(52.1)$ & $<0.001$ & $<0.001$ \\
\hline Outside/Inside & 238 & $82.8(8.2)$ & $41(17.2)$ & $84.0(7.8)$ & 44 (18.5) & $<0.001$ & 0.083 \\
\hline \multicolumn{8}{|l|}{ Department } \\
\hline Hull assembly & 291 & $88.9(8.1)$ & $128(44.0)$ & $89.7(7.6)$ & $133(45.7)$ & $<0.001$ & 0.059 \\
\hline Hull painting & 77 & $86.6(8.6)$ & $24(31.2)$ & $87.5(8.0)$ & $26(33.8)$ & $<0.001$ & 0.157 \\
\hline Sea trial & 54 & $80.0(6.7)$ & $3(5.6)$ & $81.4(6.1)$ & $3(5.6)$ & $<0.001$ & 1.000 \\
\hline Outfitting & 236 & $85.1(7.5)$ & $65(27.5)$ & $86.1(7.0)$ & $69(29.2)$ & $<0.001$ & 0.102 \\
\hline Subassembly & 188 & $90.1(8.3)$ & $103(54.8)$ & $90.7(7.9)$ & $106(56.4)$ & $<0.001$ & 0.083 \\
\hline Panel assembly & 191 & $89.1(7.7)$ & $82(42.9)$ & $90.0(7.1)$ & $92(48.2)$ & $<0.001$ & 0.002 \\
\hline Unit assembly & 213 & $91.3(6.8)$ & $118(55.4)$ & $92.0(6.7)$ & $123(57.7)$ & $<0.001$ & 0.025 \\
\hline Block painting & 87 & $87.8(9.4)$ & $33(37.9)$ & $88.6(8.9)$ & $33(37.9)$ & $<0.001$ & 1.000 \\
\hline Misc. & 238 & $82.8(8.2)$ & $41(17.2)$ & $84.0(7.8)$ & $44(18.5)$ & $<0.001$ & 0.083 \\
\hline \multicolumn{8}{|l|}{ Employment type } \\
\hline Full-time worker & 667 & $85.3(8.1)$ & $187(28.0)$ & $86.3(7.4)$ & $204(30.6)$ & $<0.001$ & $<0.001$ \\
\hline Contractor worker & 908 & $89.0(8.4)$ & $410(45.2)$ & $89.8(8.1)$ & $425(46.8)$ & $<0.001$ & 0.001 \\
\hline \multicolumn{8}{|l|}{ Occupation (job task) } \\
\hline Blasting & 18 & $89.8(7.7)$ & $8(44.4)$ & $90.6(7.5)$ & $8(44.4)$ & $<0.001$ & 1.000 \\
\hline Power & 45 & $93.2(8.0)$ & $33(73.3)$ & $93.7(7.4)$ & $33(73.3)$ & $<0.001$ & 1.000 \\
\hline Spray & 61 & $81.5(6.7)$ & $6(9.8)$ & $82.7(6.1)$ & $6(9.8)$ & $<0.001$ & 1.000 \\
\hline Touch up & 25 & $80.7(4.0)$ & $1(4.0)$ & $81.8(3.7)$ & $1(4.0)$ & $<0.001$ & 1.000 \\
\hline Heating & 30 & $100.3(5.4)$ & $29(96.7)$ & $100.8(5.4)$ & $29(96.7)$ & $<0.001$ & 1.000 \\
\hline Grinder & 172 & $96.7(6.6)$ & $147(84.9)$ & $97.3(6.5)$ & $149(86.6)$ & $<0.001$ & 0.180 \\
\hline Sea trial & 24 & $79.1(7.5)$ & $1(4.2)$ & $80.7(6.8)$ & $1(4.2)$ & $<0.001$ & 1.000 \\
\hline Signal & 30 & $80.1(6.0)$ & $1(3.3)$ & $81.9(4.6)$ & $2(6.7)$ & $<0.001$ & 0.317 \\
\hline Welding & 349 & $88.5(5.5)$ & $124(35.5)$ & $89.1(5.2)$ & $137(39.3)$ & $<0.001$ & $<0.001$ \\
\hline Material classification & 100 & $78.9(7.4)$ & $7(7.0)$ & $80.6(6.4)$ & $7(7.0)$ & $<0.001$ & 1.000 \\
\hline Cutting & 46 & $90.2(3.8)$ & $26(56.5)$ & $90.6(3.8)$ & $27(58.7)$ & $<0.001$ & 0.317 \\
\hline Fit-up & 434 & $88.5(7.4)$ & $190(43.8)$ & $89.3(7.1)$ & $200(46.1)$ & $<0.001$ & 0.004 \\
\hline Misc. & 241 & $81.5(6.4)$ & $25(10.4)$ & $82.6(6.0)$ & $29(12.0)$ & $<0.001$ & 0.046 \\
\hline
\end{tabular}

${ }^{1}$ Average of $L_{A V G}$ (standard deviation), dBA. ${ }^{2}$ Paired sample t-test for continuous data between groups $(p<0.05) .{ }^{3}$ McNemar test for categorical data within groups $(p<0.05)$.

In Table 6, when including the break time, the overall number and percentage exceeding the OELs, $90 \mathrm{dBA}$ for KOSHA guide and $89.2 \mathrm{dBA}$ for OSHA method, were significantly different between the KOSHA $(N=544,34.5 \%)$ and OSHA method $(N=608$, $38.6 \%)(p<0.05)$. Among the work-related characteristics, the exceeding numbers and percentages were significantly different between the two guidelines for workplaces (outside and inside), department (subassembly), employment type (full-time and contractor workers), and occupation (welding and fit-up) in the McNemar test $(p<0.05)$. 
Table 6. Comparison of the mean noise exposure levels by KOSHA and OSHA method (when including break time, $9 \mathrm{~h}$ ).

\begin{tabular}{|c|c|c|c|c|c|}
\hline \multirow[b]{2}{*}{ Characteristics } & \multirow[b]{2}{*}{$N$} & \multirow[b]{2}{*}{ Mean (SD) ${ }^{1}$} & \multirow{2}{*}{$\begin{array}{c}\text { KOSHA Guide } \\
>90 \mathrm{dBA} \\
{[N(\%)]}\end{array}$} & \multirow{2}{*}{$\begin{array}{c}\text { OSHA Method } \\
>89.2 \mathrm{dBA} \\
{[N(\%)]}\end{array}$} & \multirow[b]{2}{*}{$p$-Value ${ }^{2}$} \\
\hline & & & & & \\
\hline Overall & 1575 & $87.3(7.9)$ & $544(34.5)$ & $608(38.6)$ & $<0.001$ \\
\hline \multicolumn{6}{|l|}{ Work environment } \\
\hline Outside & 658 & $86.5(7.6)$ & $203(30.9)$ & $223(33.9)$ & $<0.001$ \\
\hline Inside & 679 & $89.6(7.5)$ & $302(44.5)$ & $342(50.4)$ & $<0.001$ \\
\hline Outside/Inside & 238 & $83.0(7.6)$ & $39(16.4)$ & $43(18.1)$ & 0.046 \\
\hline \multicolumn{6}{|l|}{ Department } \\
\hline Hull assembly & 291 & $88.6(7.5)$ & $117(40.2)$ & $129(44.3)$ & 0.001 \\
\hline Hull painting & 77 & $86.6(8.0)$ & $23(29.9)$ & $24(31.2)$ & 0.317 \\
\hline Sea trial & 54 & $80.4(6.0)$ & $3(5.6)$ & $3(5.6)$ & 1.000 \\
\hline Outfitting & 236 & $85.1(7.0)$ & $60(25.4)$ & $67(28.4)$ & 0.008 \\
\hline Subassembly & 188 & $89.7(7.8)$ & $86(45.7)$ & $104(55.3)$ & $<0.001$ \\
\hline Panel assembly & 191 & $88.9(7.0)$ & $76(39.8)$ & $85(44.5)$ & 0.003 \\
\hline Unit assembly & 213 & $90.9(6.6)$ & $109(51.2)$ & $120(56.3)$ & 0.001 \\
\hline Block painting & 87 & $87.8(9.0)$ & $31(35.6)$ & $33(37.9)$ & 0.157 \\
\hline Misc. & 238 & $83.0(7.6)$ & $39(16.4)$ & $43(18.1)$ & 0.046 \\
\hline \multicolumn{6}{|l|}{ Employment type } \\
\hline Full-time worker & 667 & $85.3(7.3)$ & $165(24.7)$ & $193(28.9)$ & $<0.001$ \\
\hline Contractor worker & 908 & $88.8(8.0)$ & $379(41.7)$ & $415(45.7)$ & $<0.001$ \\
\hline \multicolumn{6}{|l|}{ Occupation (job task) } \\
\hline Blasting & 18 & $89.6(7.5)$ & 7 (38.9) & $8(44.4)$ & 0.317 \\
\hline Power & 45 & $92.8(7.7)$ & $32(71.1)$ & $33(73.3)$ & 0.317 \\
\hline Spray & 61 & $81.8(6.1)$ & $6(9.8)$ & $6(9.8)$ & 1.000 \\
\hline Touch up & 25 & $81.1(3.7)$ & $1(4.0)$ & $1(4.0)$ & 1.000 \\
\hline Heating & 30 & $99.6(5.3)$ & $29(96.7)$ & $29(96.7)$ & 1.000 \\
\hline Grinder & 172 & $96.2(6.4)$ & $143(83.1)$ & $147(85.5)$ & 0.046 \\
\hline Sea trial & 24 & $79.8(6.6)$ & $1(4.2)$ & $1(4.2)$ & 1.000 \\
\hline Signal & 30 & $80.9(4.5)$ & $1(3.3)$ & $1(3.3)$ & 1.000 \\
\hline Welding & 349 & $88.1(5.2)$ & $100(28.7)$ & $127(36.4)$ & $<0.001$ \\
\hline Material classification & 100 & $79.9(6.2)$ & $5(5.0)$ & $7(7.0)$ & 0.157 \\
\hline Cutting & 46 & $89.6(3.8)$ & $17(37.0)$ & $26(56.5)$ & 0.003 \\
\hline Fit-up & 434 & $88.2(7.1)$ & $179(41.2)$ & 195 (44.9) & $<0.001$ \\
\hline Misc. & 241 & $81.4(1.1)$ & $24(10.0)$ & $27(11.2)$ & 0.083 \\
\hline
\end{tabular}

${ }^{1}$ Average of $L_{A V G}$ (standard deviation), dBA. ${ }^{2}$ McNemar test for categorical data within groups $(p<0.05)$.

Table 7 shows the mean levels of noise exposure collected for different daily monitoring schedules as it declined from more than $7 \mathrm{~h}$ (a reference value) to $4 \mathrm{~h}$, and the intracorrelation coefficients were also calculated for each schedule compared to the reference value. According to the noise exposure assessment, the average noise level $\left(L_{A V G}\right)$ measured as a reference value was $88.3 \mathrm{dBA}$, which is between 0.75 and 1.0, the "very good" criterion of the ICC over all time periods with a measurement time of 4 to $6 \mathrm{~h}$ (unmeasured time of less than $3 \mathrm{~h}$ ) [28]. The mean levels of noise exposure for several schedules of exposure monitoring collected for more than $6 \mathrm{~h}(<08: 00-15: 00,08: 00-15: 00,09: 00-16: 00)$ and for more than $5 \mathrm{~h}$ (08:00-14:00, 09:00-15:00) and 4 hper day (08:00-12:00, 09:00-14:00) were not significantly different from the reference value $(p>0.05)$. Most importantly, the mean levels with the number and proportion exceeding the exposure limit $(90 \mathrm{dBA})$ during the two schedules, 09:00-16:00 ( $\geq 6 \mathrm{~h})$ and 08:00-14:00 $(\geq 5 \mathrm{~h})$, were 88.3 dBA $(N=629$, $39.9 \%)$ and $88.1 \mathrm{dBA}(N=628,39.8 \%)$, respectively, almost equal to the reference value. 
Table 7. The mean levels of occupational noise exposure compared with an exposure limit of $90 \mathrm{dBA}$ $(8 \mathrm{~h})$, excluding break period, by increasing an hour in different monitoring schedules.

\begin{tabular}{|c|c|c|c|c|c|}
\hline \multirow{2}{*}{$\begin{array}{c}L_{A V G} \\
(\mathbf{N}=\mathbf{1 5 7 5})\end{array}$} & \multirow{2}{*}{ Mean (SD) ${ }^{1}$} & \multirow{2}{*}{$\mathrm{ICC}^{2}$} & \multicolumn{2}{|c|}{$>90 \mathrm{dBA}(8 \mathrm{~h})$} & \multirow{2}{*}{$p$-Value } \\
\hline & & & $\mathbf{N}$ & $\%$ & \\
\hline Reference value & $88.3(8.0)$ & - & 629 & 39.9 & - \\
\hline \multicolumn{6}{|l|}{ More than $6 \mathrm{~h}$} \\
\hline$<08: 00 \sim 15: 00$ & $88.0(8.1)$ & 0.994 & 616 & 39.1 & 0.085 \\
\hline 08:00 15:00 & $88.3(8.1)$ & 0.994 & 644 & 40.8 & 0.063 \\
\hline 09:00 16:00 & $88.3(8.2)$ & 0.995 & 629 & 39.9 & 1.000 \\
\hline \multicolumn{6}{|l|}{ More than $5 \mathrm{~h}$} \\
\hline$<08: 00 \sim 14: 00$ & $87.7(8.2)$ & 0.984 & 594 & 37.7 & 0.001 \\
\hline 08:00 14:00 & $88.1(8.3)$ & 0.984 & 628 & 39.8 & 0.922 \\
\hline 09:00 15:00 & $88.2(8.3)$ & 0.989 & 635 & 40.3 & 0.508 \\
\hline 10:00 16:00 & $87.9(8.4)$ & 0.984 & 597 & 37.9 & 0.001 \\
\hline \multicolumn{6}{|l|}{ More than $4 \mathrm{~h}$} \\
\hline$<08: 00 \sim 12: 00$ & $87.6(8.3)$ & 0.967 & 574 & 36.4 & $<0.001$ \\
\hline 08:00 12:00 & $88.0(8.4)$ & 0.967 & 616 & 39.1 & 0.256 \\
\hline 09:00 14:00 & $88.0(8.5)$ & 0.978 & 614 & 38.9 & 0.166 \\
\hline 10:00 15:00 & $87.8(8.6)$ & 0.978 & 607 & 38.5 & 0.036 \\
\hline $11: 00 \sim 16: 00$ & $87.4(8.7)$ & 0.958 & 581 & 36.8 & 0.000 \\
\hline
\end{tabular}

${ }^{1}$ Average of $L_{A V G}$ (standard deviation), dBA. ${ }^{2}$ ICC (Intraclass correlation coefficients) for continuous variable data within groups. ${ }^{3}$ McNemar test for categorical data within groups $(p<0.05)$.

Table 8 also shows the mean levels of noise exposure collected for different daily monitoring schedules as the daily monitoring periods decreased from another reference value measured for more than $8 \mathrm{~h}$ (08:00-16:00), including the lunch break hour, and the number and proportions exceeding a modified exposure limit value of $89.2 \mathrm{dBA}$ were compared. The ICC values of most daily schedules were between 0.75 and 1.00 , suggesting "very good." The mean levels of noise exposure for several monitoring schedules, $<08: 00-15: 00$ and 09:00-16:00 ( $\geq 7 \mathrm{~h})$, and 08:00-14:00 and 09:00-15:00 ( $\geq 6 \mathrm{~h})$, were not significantly different from the modified reference value $(p>0.05)$. The mean level $\left(L_{A V G}\right)$, 87.1 dBA $(N=610,38.7 \%)$, collected during a schedule of 09:00-15:000 ( $\geq 6 \mathrm{~h})$, was close to the modified reference value, $87.3 \mathrm{dBA}$.

Table 8. The mean levels of occupational noise exposure compared with an exposure limit of $89.2 \mathrm{dBA}$ $(9 \mathrm{~h})$, including break period, by increasing an hour in different monitoring schedules.

\begin{tabular}{|c|c|c|c|c|c|}
\hline \multirow{2}{*}{$\begin{array}{c}L_{A V G} \\
(\mathrm{~N}=\mathbf{1 5 7 5})\end{array}$} & \multirow{2}{*}{ Mean (SD) ${ }^{1}$} & \multirow{2}{*}{$\mathrm{ICC}^{2}$} & \multicolumn{2}{|c|}{$>89.2 \mathrm{dBA}(9 \mathrm{~h})$} & \multirow{2}{*}{$p$-Value ${ }^{3}$} \\
\hline & & & $\mathbf{N}$ & $\%$ & \\
\hline Reference value & $87.3(7.9)$ & - & 608 & 38.6 & - \\
\hline \multicolumn{6}{|l|}{ More than $7 \mathrm{~h}$} \\
\hline$<08: 00 \sim 15: 00$ & $87.1(8.0)$ & 0.994 & 598 & 38.0 & 0.140 \\
\hline $08: 00 \sim 15: 00$ & $87.4(8.1)$ & 0.994 & 627 & 39.8 & 0.018 \\
\hline 09:00 16:00 & $87.3(8.1)$ & 0.994 & 612 & 38.9 & 0.579 \\
\hline \multicolumn{6}{|l|}{ More than $6 \mathrm{~h}$} \\
\hline$<08: 00 \sim 14: 00$ & $86.7(8.1)$ & 0.985 & 567 & 36.0 & $<0.001$ \\
\hline 08:00 14:00 & $87.0(8.2)$ & 0.984 & 593 & 37.7 & 0.128 \\
\hline 09:00 15:00 & $87.1(8.3)$ & 0.989 & 610 & 38.7 & 0.816 \\
\hline 10:00 16:00 & $86.8(8.3)$ & 0.984 & 570 & 36.2 & $<0.001$ \\
\hline \multicolumn{6}{|l|}{ More than $5 \mathrm{~h}$} \\
\hline 09:00 14:00 & $86.6(8.4)$ & 0.978 & 565 & 35.9 & $<0.001$ \\
\hline $10: 00 \sim 15: 00$ & $86.5(8.5)$ & 0.978 & 553 & 35.1 & $<0.001$ \\
\hline 11:00 16:00 & $86.1(8.6)$ & 0.958 & 522 & 33.1 & $<0.001$ \\
\hline
\end{tabular}

${ }^{1}$ Average of $L_{A V G}$ (standard deviation), dBA. ${ }^{2}$ ICC (Intraclass correlation coefficients) for continuous variable data within groups. ${ }^{3}$ McNemar test for categorical data within groups $(p<0.05)$. 


\section{Discussion}

This study provides evidence that there is underestimation in the results using the KOSHA guideline, which suggests that the break periods (lunch break and preliminary preparation time to prepare for the noise exposure measurement) be taken out of the daily monitoring period when conducting noise exposure assessment in the shipbuilding processes in Korea. More importantly, there were significant differences in noise exposure levels measured in the shipbuilding workplaces depending on several work-related characteristics (e.g., measurement location, department, employment type, and detailed job tasks) when including or excluding lunch breaks and measurement preparation time. Therefore, noise exposure assessments, excluding the break periods during the exposure measurement time, could underestimate worker exposure levels because the proportions exceeding the OELs decreased. Furthermore, the exposure assessment, which increases the unmeasured time for occupational noise exposure by one hour, quantitatively demonstrated that it is best to measure continuously for at least $6 \mathrm{~h}$ (up to 3 p.m. or 4 p.m.) after starting the noise exposure measurement at 9 a.m., one hour after their job tasks.

Our study results showed three major findings. First, we conducted a noise exposure assessment according to the KOSHA guide and U.S. OSHA method during the break period (measurement preparation and lunchtime) and measured the cumulative noise exposure levels for a threshold level (TL) of $80 \mathrm{dBA}$. Of the total 1575 samples, high levels of noise exposure occurred out of 1432 (90.9\%) preparation times for measurement and $1359(86.9 \%)$ lunchtimes. These results indicate that the source of noise exposure exceeded the noise exposure limit during the break time during shipbuilding processes, and workers were indirectly exposed to noise generated during the break time when they were not wearing hearing protection equipment such as earplugs. Second, the noise exposure level decreased by approximately $1 \mathrm{dBA}$ (lunchtime $0.8 \mathrm{dBA}$, preparation time $0.2 \mathrm{dBA}$ ) when the break time was included in the daily exposure measurement time, while the average noise level $\left(L_{A V G}\right)$ during the measurement time was significantly increased when the rest time was not included.

Furthermore, when comparing noise exposure levels, painting-related departments (prior and hull painting, etc.) and job tasks (spray, touch-up, power) were often exposed to relatively high levels of noise during the break periods, resulting in fewer differences from the average values than other job tasks. In fact, we observed many cases where the inspection was planned after the lunch break, and several job tasks, including blasting, power, spraying, and touch-up inside the painting shop blocks, engine rooms, and tanks, were inevitably carried out during the lunch break or after taking small lunch boxes in the actual workplaces. In the shipbuilding workplaces, a variety of hazardous agents (e.g., welding fume, metals, organic solvents, etc.), including noise, were mostly generated during several processes and operations, but the dilution ventilation system using air supply was employed. In this regard, high levels of background noise were generated since the air blower devices were installed near the site's entrance and operated to quickly dry the painted ships and parts $24 / 7$, which were the major source of increased noise exposure levels. Therefore, various job tasks related to the painting departments were shown to be more exposed to high levels of background noise, including noise from working on-site air tools and air emissions for painting, drying, or grinding on average, and were less different within the groups of workers. As shown in Tables 5 and 6, the mean levels and exceeding number and percentages for most workers with some characteristics (e.g., work environment, department, and job tasks) were not significantly different between the KOSHA guide and OSHA method in the McNemar test.

Third, the noise exposure assessment strategies under the KOSHA guideline were underestimated by approximately $2 \%$ (excluding break time) and $4 \%$ (including break time) in the number and ratios exceeding the exposure limit compared to the U.S. OSHA method. The average noise level measured by the OSHA method was $88.3 \mathrm{dBA}$ and 629 $(39.9 \%)$, while the average noise level measured by the KOSHA guideline was $87.4 \mathrm{dBA}$ and $597(37.9 \%)$, respectively. When conducting the noise exposure assessment, including 
break times, the average noise level $\left(L_{A V G}\right)$ was the same, but the numbers and proportions exceeding the exposure limit value were underestimated by the KOSHA guide (34.5\%) compared to the OSHA method (38.6\%). These results were due to no modification of the occupational exposure limit for working hours exceeding 8 hours in the KOSHA guide. Furthermore, the measurement time was reduced (i.e., an increase in the unmeasured time) to a baseline of exposure sampling with less than 1 hour of unmeasured time, and the results of the noise exposure monitoring time were the most reliable for 6 hours (to 3 p.m. or 4 p.m.) after the beginning of the daily workday.

In a number of previous studies, daily working hours were found to be the most important determinant of occupational noise exposure along with each workload of job tasks, and a couple of studies quantitatively evaluating noise exposure levels during break hours have reported that there were significant effects on noise intensity, especially for shipbuilding processes, including high-frequency noise, indicating high levels of sound pressure in all workplace areas $[29,30]$. Severe, temporary hearing loss (TTS) results in longer recovery times, and the fastest recovery is within 30 or $60 \mathrm{~min}$. Changes in hearing values over time after initial exposure have been reported to be faster than those without hearing protection $[8,31]$. Therefore, it is recommended to establish management and reduction measures for major noise sources during the break time. Another study suggested a method of calibrating abnormal tasks (working for more than $8 \mathrm{~h}$ ) during a noise exposure assessment, using mathematical equations rather than calibrating occupational exposure criteria, to calibrate DOSE (\%) during measurement time and then convert it to an average noise level for $8 \mathrm{~h}$. In addition, the average and maximum 8-h TWA noise exposure values were $84.58 \mathrm{dBA}$ and $93.01 \mathrm{dBA}$, respectively, and the percentage exceeding the Korean legal exposure limit was approximately $15.94 \%$ in the transport equipment manufacturing industry, including the shipbuilding industry. Decisions can be made based on the results of a noise exposure assessment to prevent noise exposure, such as hearing preservation programs at workplaces in the shipbuilding industry. For example, in the United States, all noise above $80 \mathrm{dBA}$ should be measured to determine the need for hearing protection programs [32]. On the other hand, the Korean Ministry of Employment and Labor's noise exposure limit is unclear regarding whether the exposure limits should be modified for noise work for at least $0.25 \mathrm{~h}(115 \mathrm{dBA})$ and up to $8 \mathrm{~h}(90 \mathrm{dBA})$. To prevent noise-induced heating loss, hearing protection devices (HPDs) should be continuously worn to reduce the exposure intensity and frequency from noise sources [33].

Our study has two strengths. First, noise exposure assessment was conducted for a total of 1575 full-time and contract workers employed at a large shipbuilding company in Korea. Face-to-face interviews were conducted with these workers during the noise exposure measurement in the morning of each day, and detailed work-related information about departments, workplaces, job tasks, and occupations was collected and reviewed. The collected qualitative information was also combined with the quantitative exposure data and recorded in a work environment monitoring report, which was used to classify individual workers into similar exposure groups (SEGs) and to evaluate and compare the average noise levels by each group. Furthermore, we characterized the exposure profile for each group of workers in the shipbuilding process under four different exposure scenarios: when excluding break times during the daily noise measurement time or when including break times, only preliminary preparation or lunchtimes. It is expected that exposure sources (e.g., grinder, tool noise, compressed air vent noise, alarm sound, etc.) can come from various job tasks during the break time. Using both qualitative and quantitative information to improve the quality of the working environment can reduce potential exposure to noise for other workers as much as possible.

Second, the average noise exposure level by job was quantitatively compared using two methods, the KOSHA guide in Korea and the OSHA method in the United States, and the average noise levels were calculated by abnormal work duration (over $8 \mathrm{~h}$ ). In addition, the model simulations were conducted in two different situations, with or without break times, with an increase in the daily monitoring schedules by one hour. As a result, we were 
able to suggest the most relevant daily monitoring schedule for real-world workplaces in Korea. Using this approach, we derived similar results consistent with several previous studies, comprehensively identifying the work-related characteristics of all possible exposures during the daily working time and minimizing any systematic error or mistake in our noise exposure monitoring results.

However, our study has limitations. First, this is a case study based on a noise exposure assessment of some workers at large shipbuilding workplaces in a certain area in Korea, thus there are limits in generalizing our results to all manufacturing workers or theorizing about occupational noise exposure in other workplaces and different industries. Furthermore, we used historical exposure data recorded over the last three years from 2016 to 2018 and collected with the limited information on some determinants of occupational noise exposure for currently active workers in 2019, not former workers. Therefore, we have not fully investigated past work environment conditions, occupational exposure levels to various risk factors (e.g., dust, organic compounds, metals, etc.), other types of work performed during the processes, or other characteristics and patterns of noise exposure in the shipbuilding industry in the past. Nevertheless, the characteristics of break time during job tasks in the shipbuilding processes in Korea were quantitatively analyzed, and exposure profiles for occupational noise exposure classified by SEGs were also identified. Furthermore, it is of great significance that comprehensive noise exposure evaluation methods were presented by comparing the results using domestic and U.S. methods to identify the most appropriate daily exposure monitoring schedule (timing).

\section{Conclusions}

This study showed that workers employed at a large shipbuilding company in Korea were exposed to high levels of occupational noise during break periods, especially for those working in heating, grinding, and power processes in several painting-related departments. Furthermore, when conducting noise exposure assessments according to the KOSHA guide, we found evidence that exclusion of break times is insufficient; thus, occupational noise exposure levels were underestimated. By comparison with the results of the exposure assessment using the U.S. OSHA's method, we suggest that the most reliable schedule of daily noise exposure measurement should include the break time and must be measured continuously for at least six consecutive hours after the beginning of the job tasks. Therefore, it is necessary to conduct further studies to identify the most integrated exposure assessment strategy and daily monitoring schedule that are applicable to other workers with various job tasks in different industries in the future.

Author Contributions: Conceptualization, J.S., K.L. and H.K.; methodology, J.S., K.L. and H.K.; data curation, J.S., S.L. and K.L.; formal analysis, J.S. and K.L.; investigation, J.S., K.L. and H.K.; resources, J.S. and K.L.; software, J.S., S.L. and K.L.; validation, J.S., S.L., K.L. and H.K.; visualization, J.S. and S.L.; writing—original draft, J.S. and S.L.; writing—review and editing, J.S., S.L., K.L. and H.K.; project administration, K.L. and H.K.; supervision, H.K. All authors have read and agreed to the published version of the manuscript.

Funding: This study received no external funding.

Institutional Review Board Statement: The study was conducted according to the guidelines of the Declaration of Helsinki and approved by the Institutional Review Board (IRB) of the Catholic University of Korea, College of Medicine, Seoul, Korea (IRB approval No. MC13QASI0043).

Informed Consent Statement: The informed consent was exempted due to the secondary use of existing exposure monitoring data and related information on the work environment, department, and job duties for all shipbuilding workers (study subjects). No identifiable information or biospecimen was collected in this study.

Data Availability Statement: The data presented in this study are available from the corresponding author upon reasonable request.

Conflicts of Interest: The authors declare that there is no conflict of interest. 


\section{References}

1. Nelson, D.I.; Nelson, R.Y.; Concha-Barrientos, M.; Fingerhut, M. The global burden of occupational noise-induced hearing loss. Am. J. Ind. Med. 2005, 48, 446-458. [CrossRef] [PubMed]

2. Lee, J.H. Occupational diseases of noise exposed workers. Hanyang Med. Rev. 2010, 30, 326-332. [CrossRef]

3. Basner, M.; Babisch, W.; Davis, A.; Brink, M.; Clark, C.; Janssen, S.; Stansfeld, S. Auditory and non-auditory effects of noise on health. Lancet 2014, 383, 1325-1332. [CrossRef]

4. Jang, E.C. Occupational Noise Exposure and Serum Lipids in Manufacturing Company Workers. Soonchunhyang Med. Sci. 2018, 24, 188-195. [CrossRef]

5. Oh, M.; Shin, K.; Kim, K.; Shin, J. Influence of noise exposure on cardiocerebrovascular disease in Korea. Sci. Total Environ. 2019, 651, 1867-1876. [CrossRef] [PubMed]

6. Khosravipour, M.; Abdollahzad, H.; Khosravi, F.; Rezaei, M.; Mohammadi Sarableh, H.; Moradi, Z. The Association of Occupational Noises and the Prevalence of Metabolic Syndrome. Ann. Work Expo. Health 2020, 64, 514-521. [CrossRef] [PubMed]

7. Kim, M.G.; Ahn, Y.-S. The relationship between occupational noise exposure and hypertension using nearest age-matching method in South Korea male workers. Cogent Eng. 2021, 8, 1909798. [CrossRef]

8. Kang, B.; Kim, H. Recovery From Tempory Threshold Shifts after Short Term Exposure to Various Noise. Ocean Underw. Med. 1983, 5, 43-56.

9. Kwak, M.; Lee, J.; Kim, J.; Urm, S.; Kim, D.; Son, B.; Lee, C. Evaluation on Hearing Conservation Program in the Noisy Industries. J. Prev. Med. Public Health 1997, 30, 815-829.

10. Jang, J.-K.; Chung, K.-J. Work environment management and measurement measures for reducing occupational noise exposure. Occup. Health 2008, 246, 41-42.

11. Tao, L.; Zeng, L.; Wu, K.; Zhang, H.; Wu, J.; Zhao, Y.; Li, N.; Zhao, Y. Comparison of four task-based measurement indices with full-shift dosimetry in a complicated noise environment. Int. J. Ind. Ergon. 2016, 53, 149-156. [CrossRef]

12. KOSHA. Occupational noise exposure assessment in the workplaces. In KOSHA Guide; W-23-2016; Korea Occupational Safety and Health Agency (KOSHA), 2016. Available online: https:/ /www.kosha.or.kr/kosha/data/guidanceDetail.do (accessed on 23 June 2019).

13. Driscoll, D.P. Noise exposure assessment for extended work shifts: What are the options. UPDATE 2005, 17, 5-8.

14. Kim, K.-Y.; Kang, T.; Lee, S.G.; Park, H.D.; Jeong, J.Y. A review of a system for improving the reliability of domestic measurement results regarding the work environment. J. Korean Soc. Occup. Environ. Hyg. 2017, 27, 87-96. [CrossRef]

15. Jeong, J.Y.; Kang, T.S.; Lee, S.G.; Park, H.D.; Kim, K.Y. An improvement plan for a workplace monitoring system through random selection of workplaces and unnoticed measurement inspection. J. Korean Soc. Occup. Environ. Hyg. 2017, 27, 105-114.

16. Sayler, S.K.; Roberts, B.J.; Manning, M.A.; Sun, K.; Neitzel, R.L. Patterns and trends in OSHA occupational noise exposure measurements from 1979 to 2013. Occup. Environ. Med. 2019, 76, 118-124. [CrossRef]

17. Hwang, G. A Study on the Registration of Workplaces subjected to Work Environment Measurement to Expand it's Coverage. J. Korean Soc. Occup. Environ. Hyg. 2020, 30, 299-305.

18. Lawton, B.W. Commentary: The 1971 BOHS Hygiene Standard for Wide-band Noise. Ann. Occup. Hyg. 2003, 47, 255-259. [CrossRef]

19. AIHA. American Industrial Hygiene Association White Paper: A Generic Exposure Assessment Standard. Am. Ind. Hyg. Assoc. J. 1994, 55, 1009-1013.

20. OSHA, U.S. OSHA Technical Manual (OTM) Section III: Chapter 5-Noise; Department of Labor: 2013. Available online: https: //www.osha.gov / otm/section-3-health-hazards/chapter-5 (accessed on 23 June 2019).

21. Seixas, N.S.; Sheppard, L.; Neitzel, R. Comparison of task-based estimates with full-shift measurements of noise exposure. AIHA J. 2003, 64, 823-829. [CrossRef]

22. Brueck, S.E.; Prince Panaccio, M.; Stancescu, D.; Woskie, S.; Estill, C.; Waters, M. Noise Exposure Reconstruction and Evaluation of Exposure Trends in Two Large Automotive Plants. Ann. Occup. Hyg. 2013, 57, 1091-1104. [CrossRef]

23. Middendorf, P.J. Surveillance of occupational noise exposures using OSHA's Integrated Management Information System. Am. J. Ind. Med. 2004, 46, 492-504. [CrossRef]

24. Roh, Y.; Yim, H.; Kim, S.; Park, H.; Jung, J.; Park, S.; Kim, H.; Chung, C.; Lee, W. Recommendation and current status in exposure assessment using monitoring data in ship building industry-Focused on the similar exposure group(SEG). J. Korean Soc. Occup. Environ. Hyg. 2001, 11, 126-134.

25. Song, J.-H.; Hong, S.-Y.; Lee, Y.-S.; Kwon, H.-W. Computational Analysis on the Noise Characteristics of Ship Large Duct. J. Korean Soc. Mar. Environ. Saf. 2015, 21, 751-758. [CrossRef]

26. Huh, J.-H.; Cho, K.-S.; Ahn, K.-D.; Lee, B.-K. Estimation of Noise Exposure dureation by a Noise Dosimeter. Soonchunhyang Med. Sci. (SMS) 2000, 6, 23-29.

27. Choe, H.-G.; Shin, Y.-I.; Yang, B.-S.; Lee, Y.-W.; Kim, K.-H. A Study on the Characteristics of Noise in Small Boats. J. Korea Ship Safrty Technol. Auth. 2003, 11, 33-42.

28. Kong, K.A. Statistical methods: Reliability assessment and method comparison. Ewha Med. J. 2017, 40, 9-16. [CrossRef]

29. Bhumika, N.; Prabhu, G.; Ferreira, A.; Kulkarni, M. Noise-Induced Hearing Loss Still a Problem in Shipbuilders: A Cross. Sectional Study in Goa, India. Ann. Med. Health Sci. Res. 2013, 3, 1-6. [CrossRef]

30. Alexopoulos, E.C.; Tsouvaltzidou, T. Hearing loss in shipyard employees. Indian J. Occup. Environ. Med. 2015, $19,14$. 
31. Kim, J.-M. Effects of occupational noise exposure on human health in the work environments. Korean Soc. Noise Vib. Eng. 2007, 29, 131-137.

32. Tak, S.; Davis, R.R.; Calvert, G.M. Exposure to hazardous workplace noise and use of hearing protection devices among US workers-NHANES, 1999-2004. Am. J. Ind. Med. 2009, 52, 358-371. [CrossRef] [PubMed]

33. Song, H.; Jeong, S.; Lee, E.; Alsabbagh, N.; Lee, J.; You, S.; Kwak, C.; Kim, S.; Han, W. Types of Hearing Protection Devices and Application. Korean J. Otorhinolaryngol. Head Neck Surg. 2019, 62, 1-14. [CrossRef] 